\title{
Repelência e deterrência na oviposição de Bemisia tabaci biótipo B pelo uso de extratos vegetais em Cucurbita pepo L.
}

\author{
SILVA, J.P.G.F.; ZACHÉ, R.R.C.*; BALDIN, E.L.L.; OLIVEIRA, F.B.; VALTAPELI, E.R. \\ Departamento de Produção Vegetal - Defesa Fitossanitária, Faculdade de Ciências Agronômica, FCA/UNESP, \\ Fazenda Experimental Lageado, Caixa Postal 237, CEP: 18610-307, Botucatu-Brasil *ronelzagro@yahoo.com.br
}

\begin{abstract}
RESUMO: Bemisia tabaci biótipo B é um dos principais insetos-praga na cultura da abobrinha (Cucurbita pepo L.). O manejo dessa mosca-branca tornou-se grande desafio aos agricultores, uma vez que esta apresenta rápida capacidade de desenvolver resistência a diferentes classes de inseticidas. Como alternativa vem sendo investigado o uso de extratos vegetais com atividades inseticida e/ou insetistática, os quais têm revelado resultados promissores no combate a inseto. O presente trabalho teve por objetivo avaliar os possíveis efeitos de sete extratos provenientes de cinco espécies vegetais, Ruta graveolens L. (folhas), Azadirachta indica A. Juss. (folhas + ramos), Trichilia pallida Swartz (ramos), T. pallida (folhas), A. indica (amêndoas), Chenopodium ambrosioides L. (inflorescências + ramos+ folhas) e Mentha pulegium L. (folhas), sobre Bemisia tabaci biótipo $B$ em abobrinha, por meio de testes de repelência e deterrência para oviposição. Em teste com chance de escolha, avaliou-se a atratividade e determinou-se o índice de repelência após 6,24 e 48 horas da aplicação dos extratos. A oviposição foi verificada após a terceira contagem do número de adultos. O extrato à base de folhas de $M$. pulegium mostrou repelência e deterrência à oviposição de $B$. tabaci biótipo $\mathrm{B}$, podendo ser recomendado como alternativa para o manejo do inseto.
\end{abstract}

Palavras-chave: Curcubitaceae, mosca-branca, extratos vegetais, manejo alternativo

\begin{abstract}
Repellence and deterrence on oviposition of Bemisia tabaci biotype $B$ by the use of vegetal extracts in Cucurbita pepo L. Bemisia tabaci biotype $B$ is one of the main pests in squash (Cucurbita pepo L.). The management of this whitefly has become a major challenge to growers, since they have the ability to quickly develop resistance to different classes of insecticides. Alternatively, the use of plant extracts with insecticide and/or insectistatic activities has been investigated, showing promising results for the whitefly control. The present study evaluated the possible effects of seven extracts from five plant species, Ruta graveolens L. (leaves), Azadirachta indica A. Juss. (leaves + branches), Trichilia pallida Swartz (branches), T. pallida (leaves), A. indica (almonds), Chenopodium ambrosioides L. (inflorescence + leaves + branches) and Mentha pulegium L. (leaves) on Bemisia tabaci biotype B in squash, by assays of repellence and oviposition deterrence. In free choice tests, the attractiveness and determination of the rate of repellence (with 6, 24 and 48 hours after application of the extracts) were evaluated. The oviposition was observed after the third counting of the number of adults. The extract of leaves of $M$. pulegium showed repellence and oviposition deterrence to $B$. tabaci biotype $B$ and may be recommended as an alternative in the insect management.
\end{abstract}

Key words: Curcubitaceae, whitefly, plant extracts, alternative management

\section{INTRODUÇÃO}

As cucurbitáceas ocupam lugar de destaque dentre as hortaliças no Brasil, uma vez que seus frutos constituem-se como grandes fontes de vitaminas $\mathrm{Ae}$ D. As sementes, muito ricas em proteínas, podem ser também utilizadas na extração de óleos comestíveis, além de serem consumidas diretamente
(Blanco et al., 1997).

A ocorrência de pragas, doenças e o prateamento das folhas da aboboreira limitam a produção, causando prejuízos aos agricultores. Dentre as pragas associadas à cultura, destaca-se a moscabranca Bemisia tabaci (Gennadius) biótipo B, também

Recebido para publicação em 19/04/2010

Aceito para publicação em 03/07/2011

Rev. Bras. PI. Med., Botucatu, v.14, n.1, p.76-83, 2012. 
denominada B. argentifolii Bellows (Van Lenteren \& Noldus, 1990; Byrne \& Bellows Júnior 1991; Liu \& Oeting, 1993; Oliveira \& Silva, 1997; Villas Bôas et al., 1997; Summers \& Stapleton, 2002).

No Brasil, desde o início da década de 1990, têm sido observadas altas populações de $B$. tabaci biótipo B colonizando Cucurbita. pepo, C. moschata e C. maxima, geralmente associadas à incidência de prateamento das folhas (Lourenção \& Nagai, 1994; França et al., 1996; Alves et al., 2005). Summers \& Stapleton (2002) confirmam a ocorrência dessa mosca-branca nessas espécies, e a ressaltam como uma das principais pragas dessas culturas.

Ninfas e adultos de mosca-branca introduzem os estiletes bucais nos vasos floemáticos, de onde sugam a seiva, ao mesmo tempo em que injetam saliva nos tecidos. Durante a alimentação são retirados nutrientes das plantas, podendo ocasionar redução no crescimento, desfolha, diminuição na produtividade e, em alguns casos, a morte das mesmas (Flint, 1995; Norman et al., 1996; Villas Bôas et al., 1997). Quando ocorrem altas infestações do inseto, as perdas causadas pela sucção de seiva podem chegar a $50 \%$ da produção (Villas Bôas et al., 1997).

O "honeydew" excretado pelas moscasbrancas possibilita a colonização de fungos do gênero Capnodium, levando à formação da fumagina, que interfere na fotossíntese, causando perda de qualidade do produto final (Flint, 1995; Norman et al., 1996; Villas Bôas et al., 1997). B. tabaci biótipo B tem causado danos expressivos por meio da alimentação e do depósito de grandes quantidades de "honeydew", devido aos altos níveis populacionais alcançados em curto espaço de tempo, acarretando prejuízos de bilhões de dólares (Brown et al., 1995).

O prateamemento-das-folhas em Cucurbita spp é uma anomalia relacionada à alimentação das ninfas, provavelmente resultante da injeção de toxinas (Yokomi et al., 1990a, b; Hoelmer et al., 1991a, b).

Conforme Schmalstig \& McAuslane (2001), o desenvolvimento do prateamento das folhas mais jovens, que não estiveram em contato com as ninfas, se dá por meio de translocação, via floema, de substâncias tóxicas provenientes de áreas infestadas. Essa anomalia provoca queda na produtividade, deixando os frutos descoloridos em relação aos normais (Nagai et al., 1992). Os sintomas aparecem três a cinco dias após a exposição de folhas às ninfas (Yokomi et al., 1990a; Hoelmer et al., 1991a; b) ou nove a onze dias após a exposição a adultos (Hoelmer et al., 1991a, b).

Além dessas anomalias, $B$. tabaci biótipo $B$ transmite os geminivírus, Squash Leaf Curl Virus (SLCV) e Watermelon chlorotic stunt virus (WCSV) em cultivares de $C$. foetidissima, C. maxima, $C$. moschata e C. pepo, ocasionando severa ondulação e manchas aneladas amarelas, tornando a folha transparente quando exposta contra o sol. Em muitos casos, as plantas, mesmo produzindo flores, não produzem frutos (Brown et al., 1992).

Brown et al. (2002) notificaram o surgimento de nova espécie de begomovirus, Cucurbit leaf curl virus-Arizona (CuLRV-AZ) infectando cucurbitáceas, dentre elas abobrinha (C. pepo), melão (Cucumis melo) e abóbora (C. maxima), também infectando feijão (Phaseolus vulgaris) e fumo (Nicotiana spp.) transmitido por B. tabaci.

O manejo de $B$. tabaci biótipo $B$ tem se tornado um desafio aos agricultores, pois os danos ocasionados pelo inseto têm aumentado significativamente em diferentes regiões geográficas, inclusive no Brasil. Alguns autores (Horowitz \& Ishaaya, 1995; Silva et al., 2009) também ressaltam sobre a inconveniência do uso continuado dos inseticidas para o controle de $B$. tabaci biótipo $B$, devido à elevada capacidade do inseto em desenvolver resistência a muitas classes de inseticidas.

Na busca por táticas alternativas e menos agressivas para o manejo de moscas-brancas em culturas, a utilização de extratos vegetais com atividades inseticida e/ou insetistática, tem revelado resultados promissores com $B$. tabaci biótipo B (Cunha et al., 2005; Bogorni \& Vendramim, 2005; Baldin et al., 2007b). Dessa forma, o presente trabalho teve por objetivo avaliar os possíveis efeitos de sete extratos vegetais provenientes de cinco espécies vegetais sobre Bemisia tabaci biótipo B em abobrinha, através de testes de repelência e deterrência para oviposição.

\section{MATERIAL E MÉTODO}

Os experimentos foram conduzidos no Departamento de Produção Vegetal, Defesa Fitossanitária da Faculdade de Ciências Agronômicas (FCA) - Campus de Botucatu/SP- UNESP, durante o ano de 2009.

\section{Criação estoque de Bemisia tabaci (Genn., 1889) biótipo $B$ \\ Para a realização do trabalho foi mantida} criação do inseto em casa-de-vegetação, iniciada com indivíduos provenientes do Setor de Entomologia do Instituto Agronômico de Campinas (IAC). A espécie de mosca-branca foi previamente identificada pela $\mathrm{Dr}$ Judith K. Brown, da Universidade do Arizona, EUA. Como fonte de alimentação, foram utilizadas plantas de couve-manteiga e soja, acondicionadas em vasos de 3 L. Estes vasos foram monitorados semanalmente e as plantas deterioradas substituídas por outras sadias. 


\section{Obtenção de extratos vegetais}

Para o preparo dos sete extratos utilizados foram coletadas diferentes estruturas das plantas de cinco espécies vegetais, conforme ilustra a Tabela 1. As estruturas provenientes de nim (A. indica) e catiguá ( $T$. pallida) foram coletadas junto à ESALQ/ USP, Piracicaba- SP, no mês de setembro de 2009 sob a supervisão do Prof. Dr. José Djair Vendramim; as demais foram obtidas e identificadas junto ao Departamento de Horticultura da FCA/UNESP, Botucatu- SP, no mesmo período.

Os materiais coletados foram secos em estufa com circulação de ar a $40^{\circ} \mathrm{C}$ por $48 \mathrm{~h} \mathrm{e}$ posteriormente triturados em moinho elétrico de facas até a obtenção dos pós, os quais foram armazenados separadamente por espécie e estrutura vegetal em recipientes escuros, hermeticamente fechados. Os extratos foram preparados misturando-se, com o auxílio de um agitador, $3 \mathrm{~g}$ de pó de cada material a $100 \mathrm{~mL}$ de água destilada (Souza \& Vendramim, 2000, 2001; Baldin et al., 2007a). As suspensões resultantes foram mantidas à temperatura ambiente e sob agitação por $24 \mathrm{~h}$, visando à extração dos compostos hidrossolúveis. Após isso, as soluções foram filtradas em tecido voil ( 5 camadas), originando os extratos aquosos a 3,0\% (peso/volume) e a testemunha foi composta por água destilada.

\section{Atratividade e preferência para oviposição}

A atratividade e a oviposição de $B$. tabaci biótipo $B$ em plantas de abobrinha pulverizadas com extratos vegetais foi avaliada por meio de teste com chance de escolha. Para tanto, o genótipo de abobrinha Caserta Cac Melhorada foi semeado em vaso de polietileno $(1 \mathrm{~L})$ contendo terra de barranco, esterco de curral e areia na proporção de 1:1:1 e 6,30 g de adubo na formulação 4-14-8. Padronizou-se o plantio de três sementes por vaso e após a germinação, foi realizado o desbaste, deixando-se apenas uma planta.

Vinte dias após a semeadura (quando as plantas apresentavam as primeiras duas folhas verdadeiras) e com auxílio de borrifador manual (200 $\mathrm{mL}$ ), as plantas foram pulverizadas com os respectivos extratos até o ponto de escorrimento $(75 \mathrm{~mL})$, sendo essa quantidade usada em todos os testes.

Após 15 minutos da aplicação, os vasos com as plantas de abobrinha foram distribuídos de forma equidistante e aleatória, em círculo, no interior de gaiolas teladas $(1,0 \times 1,0 \times 1,0 \mathrm{~m})$. Os vasos foram espaçados em cerca de $20 \mathrm{~cm}$, evitando-se o contato entre as folhas contendo tratamentos diferentes. Em seguida, liberou-se no chão, e ao centro das gaiolas, uma proporção de 50 casais da mosca-branca por vaso. A atratividade foi avaliada 6, 24 e 48 horas após a liberação dos insetos, contando-se, com o auxílio de espelho, o número de adultos presentes na face abaxial de uma folha previamente marcada por planta.

Após as contagens do número de adultos, foi também calculado o índice de repelência:

$$
\mathrm{IR}=2 \mathrm{~T} /(\mathrm{T}+\mathrm{P})
$$

onde: $\mathrm{IR}=$ índice de repelência; $\mathrm{T}=\mathrm{n}$ - de adultos no tratamento avaliado (extrato) e $\mathrm{P}=\mathrm{n}$ o de adultos no tratamento padrão, água destilada.

Os valores de IR variam entre zero e dois, sendo que $I R=1$ indica atração semelhante entre $o$ extrato avaliado (extrato-teste repelente) e o padrão (água destilada), IR $<1$ corresponde a maior repelência pelo extrato e IR $>1$ indica menor repelência pelo extrato avaliado em relação ao padrão. Os tratamentos foram classificados comparando-se o índice obtido no extrato avaliado com o da testemunha, adotando-se o erro padrão (EP) da média do ensaio para diferenciação. Esse índice é uma adaptação da fórmula citada por Lin et al. (1990), utilizado por Baldin \& Lara (2001).

Para se determinar a preferência para oviposição, após a terceira contagem (48 h) do número de adultos, as folhas marcadas foram retiradas das plantas e conduzidas ao laboratório, onde com o auxílio de microscópio estereoscópico (aumento de 40x) contou-se o número de ovos presentes na fase abaxial

TABELA 1. Relação de espécies, famílias e respectivas estruturas vegetais utilizadas na confecção dos extratos. Botucatu, SP, 2009.

\begin{tabular}{cccc}
\hline Extrato & Espécie & Família & Parte utilizada \\
\hline 1 & Azadiracta indica A. Juss & Meliaceae & Amêndoa \\
2 & Azadiracta indica A. Juss & Meliaceae & Folha + Ramo \\
3 & Trichilia pallida Swartz & Meliaceae & Ramo \\
4 & Trichilia pallida Swartz & Meliaceae & Folha \\
5 & Ruta graveolens L. & Rutaceae & Folha \\
6 & Chenopodium ambrosioides L. & Chenopodiaceae & Folha+Ramo+lnflorescência \\
7 & Mentha pulegium L. & Lamiaceae & Folha \\
\hline
\end{tabular}

Rev. Bras. PI. Med., Botucatu, v.14, n.1, p.76-83, 2012. 
das folhas. Após as contagem, a área das folhas foi medida com auxílio de medidor de área foliar LI-COR (LAI 3000A), a fim de se obter o número de ovos $\mathrm{cm}^{-}$ 2 .

Calculou-se também um índice de preferência para oviposição:

$$
\mathrm{IPO}=[(\mathrm{T}-\mathrm{P}) /(\mathrm{T}+\mathrm{P})] \times 100
$$

onde $\mathrm{T}=\mathrm{n}$ - de ovos no extrato avaliado e $\mathrm{P}=\mathrm{n}$ de ovos no tratamento padrão, água destilada. $O$ índice varia de +100 (muito estimulante) até -100 (total deterrência), sendo o valor 0 indicativo de neutralidade.

A classificação dos extratos foi feita a partir da comparação das médias de ovos dos tratamentos com a média da testemunha (água destilada), levandose em consideração o erro padrão da média do ensaio para a diferenciação dos mesmos (Baldin et al., 2000; 2005; 2007a).

Foram efetuadas seis repetições (uma por gaiola), seguindo delineamento de blocos casualizados (DBC).

\section{Análise estatística}

Os dados obtidos foram submetidos à análise de variância pelo teste $F$, sendo as médias comparadas pelo teste de Tukey a $5 \%$ de probabilidade. Utilizou- se o programa estatístico SAS (SAS Institute, 2001).

\section{RESULTADO E DISCUSSÃO}

Analisando-se o número de adultos de moscas-brancas atraídos pelas folhas de abobrinha após 6 e 24 horas da aplicação de extratos vegetais (Tabela 2), constatou-se menor número de indivíduos nas folhas contendo o extrato de $M$. pulegium (f), diferindo significativamente do tratamento com água destilada. Embora as plantas pulverizadas com os extratos de $R$. graveolens (f), A. indica $(\mathrm{f}+\mathrm{r})$, T. pallida (r), T. pallida (f), A. indica (a) e C. ambrosioides ( $\mathrm{i}+\mathrm{r}$ $+f)$ tenham apresentado médias intermediárias de moscas-brancas atraídas, estas não diferiram da testemunha, indicando serem menos potentes que 0 extrato de $M$. pulegium na repelência à $B$. tabaci biótipo $\mathrm{B}$.

Após 48 horas da aplicação dos extratos (Tabela 2), não foram observadas diferenças estatísticas entre os tratamentos. É possível que após dois dias da aplicação, os extratos aquosos tenham reduzido seus efeitos. Isso provavelmente ocorreu devido ao uso de extratos polares (aquosos), os quais geralmente sofreram oxidação, diminuindo sai bioatividade sobre a mosca-branca.

$O$ índice de repelência (IR) obtido após 6 e 24 horas da aplicação dos extratos vegetais foi inferior a um $(\mathrm{IR}<1)$ para todos os extratos, com exceção ao $R$. graveolens, considerado neutro. O M. pulegium se destacou dos demais, indicando maior repelência sobre adultos de mosca-branca (Figuras 1 e 2). Após 48 horas da aplicação dos extratos o comportamento dos extratos foi semelhante, com exceção dos extratos de $R$. graveolens (f) e C. ambrosioides (i+ $r$ $+\mathrm{f})$ com $I R=1$, considerados semelhantes ao tratamento padrão (água destilada) (Figura 3).

Os resultados observados no teste de repelência são semelhantes aos encontrados por Baldin et al. (2007a), que verificaram que plantas de

TABELA 2. Número médio $( \pm \mathrm{EP})$ de adultos de $B$. tabaci biótipo $B$ atraídos por folhas de abobrinha pulverizadas com diferentes extratos vegetais. Botucatu, SP, 2009.

\begin{tabular}{lccc}
\hline Extrato $^{1}$ & \multicolumn{3}{c}{ № de adultos } \\
\cline { 2 - 4 } & $\mathbf{6} \mathbf{h}$ & $\mathbf{2 4} \mathbf{~}$ & $\mathbf{4 8} \mathbf{~}$ \\
\hline Testemunha & $14,7 \pm 5,36 \mathrm{a}$ & $23,5 \pm 8,05 \mathrm{a}$ & $23,3 \pm 8,4 \mathrm{a}$ \\
R. graveolens (f) & $8,0 \pm 3,13 \mathrm{a} \mathrm{b}$ & $13,7 \pm 4,79 \mathrm{a} \mathrm{b}$ & $16,2 \pm 4,7 \mathrm{a}$ \\
A. indica $(\mathrm{f}+\mathrm{r})$ & $6,7 \pm 2,32 \mathrm{a} \mathrm{b}$ & $10,5 \pm 2,94 \mathrm{a} \mathrm{b}$ & $11,0 \pm 3,3 \mathrm{a}$ \\
T. pallida ( $\mathrm{r})$ & $6,2 \pm 2,12 \mathrm{a} \mathrm{b}$ & $13,3 \pm 3,69 \mathrm{a} \mathrm{b}$ & $12,5 \pm 5,2 \mathrm{a}$ \\
T. pallida (f) & $5,2 \pm 2,04 \mathrm{a} \mathrm{b}$ & $7,8 \pm 2,44 \mathrm{a} \mathrm{b}$ & $10,2 \pm 2,1 \mathrm{a}$ \\
A. indica (s) & $5,0 \pm 1,59 \mathrm{a} \mathrm{b}$ & $9,0 \pm 2,77 \mathrm{a} \mathrm{b}$ & $11,8 \pm 4,9 \mathrm{a}$ \\
C. ambrosioides $(\mathrm{i}+\mathrm{r}+\mathrm{f})$ & $4,3 \pm 1,17 \mathrm{a} \mathrm{b}$ & $13,5 \pm 3,73 \mathrm{a} \mathrm{b}$ & $22,0 \pm 4,4 \mathrm{a}$ \\
M. pulegium (f) & $1,7 \pm 0,76 \mathrm{~b}$ & $3,3 \pm 0,76 \mathrm{~b}$ & $5,2 \pm 1,5 \mathrm{a}$ \\
\hline $\mathrm{F}$ & 2,01 & 2,22 & 2,00 \\
CV(\%) & 45,70 & 40,02 & 39,15 \\
\hline
\end{tabular}

${ }^{1}$ Legenda: $\mathrm{f}=$ folha; $r=$ ramo; $i=$ inflorescência; $a=$ amêndoa. ${ }^{2}$ Dados originais, para análise foram transformados em $(x+0,5)^{1 / 2}$. Médias seguidas de mesma letra, na coluna, não diferem entre si pelo teste de Tukey a $5 \%$ de probabilidade. 


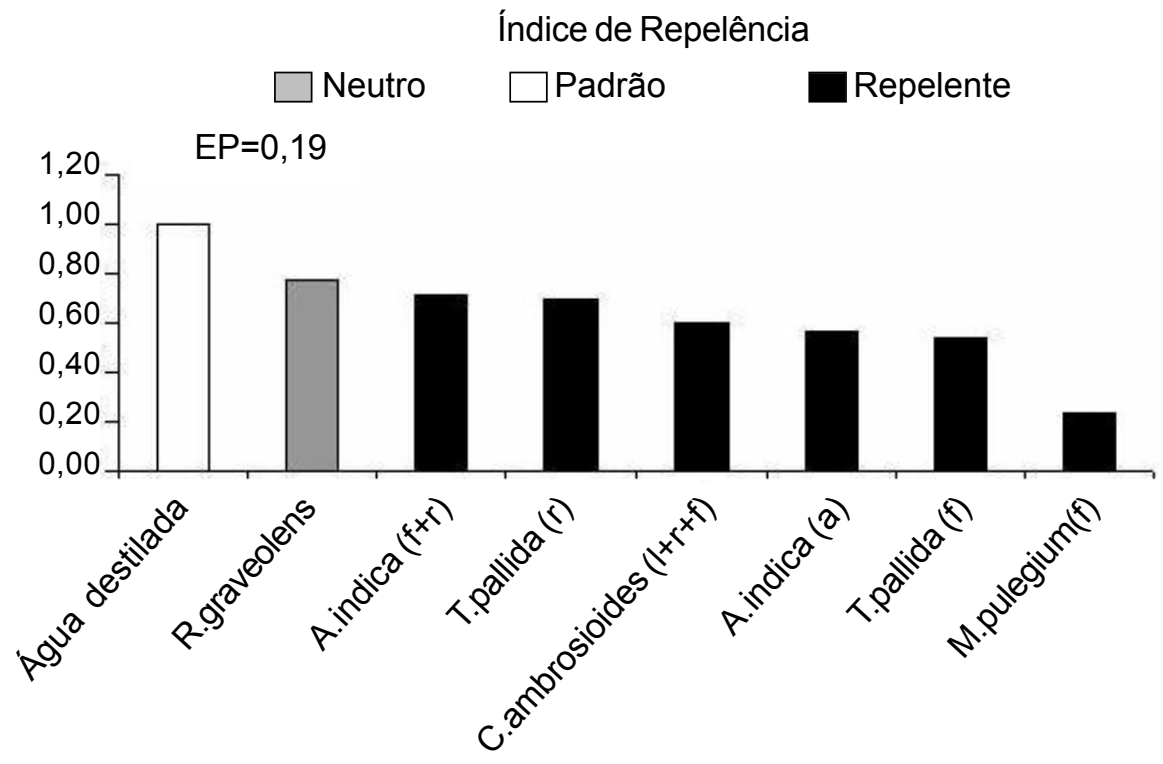

FIGURA 1. Índice de repelência de extratos sobre adultos de $B$. tabaci biótipo $B$ após 6 horas da aplicação. IR= $2 T /(T+P)$, onde: $I R=$ índice de repelência; $T=n \circ$ de adultos no tratamento avaliado e $P=n \circ$ de adultos no tratamento padrão. Botucatu, SP, 2009.

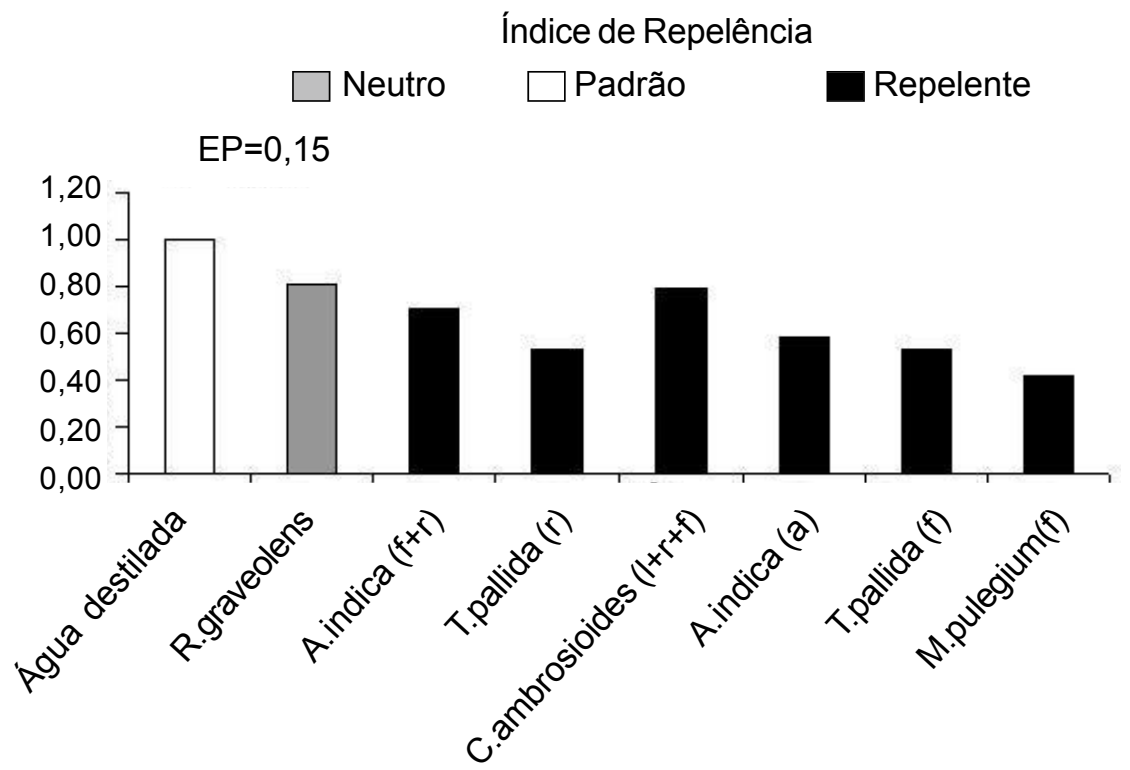

FIGURA 2. Índice de repelência de extratos sobre adultos de $B$. tabaci biótipo $B$ após 24 horas da aplicação. IR= $2 T /(T+P)$, onde: $I R=$ índice de repelência; $T=n \circ$ de adultos no tratamento avaliado e $P=n \circ$ de adultos no tratamento padrão. Botucatu, SP, 2009.

tomateiro pulverizadas com extratos provenientes de M. pulegium (f); A. indica $(f+a)$ e T. pallida $(r+f)$ foram repelentes à mesma espécie de mosca-branca, comparativamente às plantas pulverizadas com água destilada.

Em trabalho visando o controle alternativo de carunchos, Mazzonetto \& Vendramim (2003) constataram repelência à Acanthoscelides obtectus Say, quando misturaram grãos com pós provenientes de $R$. graveolens, M. pulegium, C. ambrosioides e

\section{Eucalyptus citriodora L.}

No geral, os tratamentos à base de folhas de $M$. pulegium foram mais repelentes aos adultos da mosca-branca, podendo ser recomendados como alternativa no manejo da mosca-branca em abóbora. Deve-se ressaltar que, no caso específico da moscabranca B. tabaci biótipo B em aboboreira, a baixa atratividade é de grande importância, uma vez que, evitando que o inseto chegue até a planta, evita-se também que ele se alimente e provoque 0 
Índice de Repelência

Neutro $\square$ Padrão $\square$ Repelente

$E P=0,14$

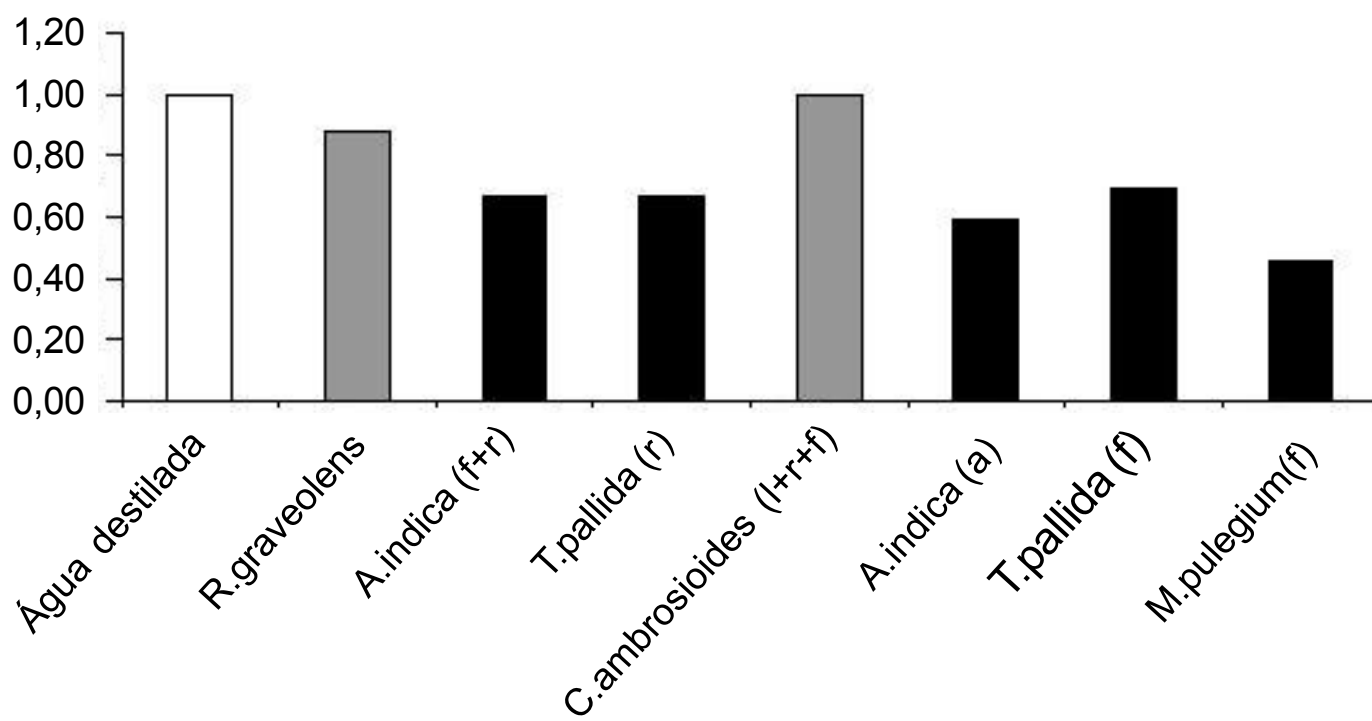

FIGURA 3. Índice de repelência de extratos sobre adultos de $B$. tabaci biótipo $B$ após 48 horas da aplicação. IR= $2 T /(T+P)$, onde: $I R=$ índice de repelência; $T=n \circ$ de adultos no tratamento avaliado e $P=n o$ de adultos no tratamento padrão. Botucatu, SP, 2009.

TABELA 3. Número médio ( $\pm \mathrm{EP}$ ) de ovos $/ \mathrm{cm}^{2}$ de $B$. tabaci biótipo $B$ contados em folhas de abobrinha e índice de preferência para oviposição (IPO), obtidos 48 horas após a aplicação de diferentes extratos vegetais. Botucatu, UNESP, 2009.

\begin{tabular}{lclc}
\hline Extrato & № de ovos $^{2}$ & \multicolumn{2}{c}{ Preferência para oviposição $^{3}$} \\
& & Índice (EP) & Classificação \\
\hline Água destilada & $11,50 \pm 2,62 \mathrm{a}$ & $00,00 \pm 0,00$ & neutro \\
R. graveolens (f) & $6,67 \pm 1,73 \mathrm{ab}$ & $-36,81 \pm 14,07$ & deterrente \\
A. indica $(\mathrm{f}+\mathrm{r})$ & $6,00 \pm 1,53 \mathrm{ab}$ & $-45,84 \pm 9,42$ & deterrente \\
T. pallida $(\mathrm{r})$ & $5,83 \pm 1,54 \mathrm{ab}$ & $-34,24 \pm 10,27$ & Deterrente \\
T. pallida (f) & $5,33 \pm 1,52 \mathrm{ab}$ & $-38,95 \pm 12,68$ & Deterrente \\
A. indica (a) & $4,50 \pm 1,34 \mathrm{ab}$ & $-29,63 \pm 15,44$ & Deterrente \\
C. ambrosioides ( $\mathrm{i}+\mathrm{r}+\mathrm{f})$ & $4,33 \pm 0,67 \mathrm{ab}$ & $-32,99 \pm 5,91$ & Deterrente \\
M. pulegium (f) & $2,00 \pm 0,82 \mathrm{~b}$ & $-71,13 \pm 5,78$ & Deterrente \\
\hline F & $2,84^{*}$ & & \\
CV (\%) & 31,84 & &
\end{tabular}

${ }^{1}$ Legenda: $f=$ folha; $r=$ ramo; $i=$ inflorescência; $a=$ amêndoa. ${ }^{2}$ Dados originais; para análise estatística foram transformados em $(x+0,5)^{1 / 2}$. Médias seguidas de mesma letra, na coluna, não diferem entre si pelo teste de Tukey a $5 \%$ de probabilidade. ${ }^{3} I P O=[(T-P) /(T+P)] \times 100$. IPO varia de +100 (muito estimulante) até -100 (total deterrência), sendo o valor 0 indicativo de neutralidade. 
prateamento foliar. De acordo com Martinez (2002), os efeitos repelentes, inseticidas e/ou insetistáticos de extratos de sementes e folhas de $A$. indica contra pragas são promissores, sendo atualmente alvo de estudos em muitos centros de pesquisa entomológica no mundo.

Comparando-se o número médio de ovos da mosca-branca em folhas de abobrinha pulverizadas com os diferentes extratos vegetais (Tabela 3), observa-se que a oviposição foi menor nas folhas tratadas com o extrato de folhas de M. pulegium (2,00 ovos $\left.\mathrm{cm}^{-2}\right)$, diferindo da testemunha ( 11,50 ovos $\left.\mathrm{cm}^{-2}\right)$ que apresentou a maior média de ovos depositados.

O comportamento de oviposição de $B$. tabaci biótipo $\mathrm{B}$ frente aos extratos de $R$. graveolens (f); $A$. indica $(\mathrm{f}+\mathrm{r})$; T. pallida $(\mathrm{r})$; T. pallida $(\mathrm{f}) ;$ A. indica $(\mathrm{a})$, C. ambrosioides $(i+r+f)$ e $M$. pulegium (f) sugere que estes tratamentos apresentam compostos polares, deterrentes à oviposição (Tabela 3). De acordo com Lara (1991), substâncias deterrentes impedem que o inseto continue a ovipositar num local devido à presença de voláteis adversos. Baseado nos índices de preferência para oviposição calculados, todos os extratos foram considerados deterrentes à oviposição do inseto, comparativamente à água destilada.

Os resultados obtidos no trabalho indicam que a pulverização de extrato à base de folhas de $M$. pulegium torna as plantas de abobrinha mais repelentes aos adultos de $B$. tabaci biótipo $B$, além de reduzir sua oviposição. Embora os resultados dos demais extratos avaliados tenham sido intermediários, estes também apresentam potencial para o manejo da mosca-branca, devendo ser melhor investigados no futuro.

Por se tratar de planta de fácil acesso, com ciclo rápido e baixo custo de produção, $M$. pulegium, vulgarmente conhecida por poejo, pode ser indicada na forma de extrato aquoso como uma alternativa viável para o manejo da mosca-branca em abobrinha, especialmente para os pequenos produtores.

\section{REFERÊNCIA}

AlVES, A.C.; LOURENÇÃO, A.L.; MELO, A.M.T. Resistência de Genótipos de Aboboreira a Bemisia tabaci (Genn.) Biótipo B (Hemiptera: Aleyrodidae). Neotropical Entomology, v.34, n.6, p.973-9, 2005. BALDIN, E.L.L.; LARA, F.M. Atratividade e consumo foliar por adultos de Diabrotica speciosa (Germ.) (Coleoptera: Chrysomelidae) em diferentes genótipos de abóbora. Neotropical Entomology, v.30, n.4, p.675-9, 2001.

BALDIN, E.L.L. et al. Controle de mosca-branca com extratos vegetais, em tomateiro cultivado em casa-devegetação. Horticultura Brasileira, v.25, n.4, p.602-6, 2007a.

BALDIN, E.L.L.; VENDRAMIM, J.D.; LOURENÇÃO, A.L.
Interaction between resistant tomato genotypes and plant extrects on Bemisia tabaci (Genn.) Biotype B. Scientia Agricola, v.64, n.5, p.476-81, 2007b.

BALDIN, E.L.L. et al. Preferência para oviposición de Bemisia tabaci biótipo "B" por genótipos de Cucurbita moschata y Cucurbita maxima. Boletin de Sanidad Vegetal, v.26, n.3, p.409-13, 2000.

BALDIN, E.L.L. et al. Resistência de genótipos de tomateiro à mosca-branca Bemisia tabaci (Gennadius) biótipo B (Hemiptera: Aleyrodidae). Neotropical Entomology, v.34, p.435-41, 2005.

BLANCO, M.C.S.G.; GROPPO, G.A.; TESSARIOLI NETO, J. Manual da Coordenadoria de Assistência Técnica Integrada. v.2. Campinas: Cati, 1997, p.7-11.

BOGORNI, P.C.; VENDRAMIM, J.D. Efeito subletal de extratos aquosos de Trichilia spp. sobre o desenvolvimento de Spodoptera frugiperda (J.E. Smith) (Lepidoptera: Noctuidae) em milho. Neotropical Entomology, v.34, p.311-7, 2005.

BROWN, J.K.; COSTA, H.S.; LAEMMLEN, F. First report of whitefly associated squash silverleaf disorder of Cucurbita in Arizona and of white streak disorder of Brassica species in Arizona and California. Plant Disease, v.76, p.434-6, 1992.

BROWN, J.K.; FROHLICH, D.R.; ROSELL, R.C. The sweetpotato or silverleaf whiteflies: biotypes of Bemisia tabaci or a species complex? Annual Review of Entomology, v.40, p.511-34, 1995.

BYRNE, D.N.; BELLOWS JUNIOR, T.S. Whitefly biology. Annual Review of Entomology, v.36, p.431-57, 1991.

CUNHA, U.S. et al. Potencial de Trichilia pallida Swartz (Meliaceae) como fonte de substâncias com atividade inseticida sobre a traça do tomateiro, Tuta absoluta (Meyrick) (Lepidoptera: Gelechiidae). Neotropropical Entomology, v.34, p.667-73, 2005.

FLINT, M.L. Whiteflies in California: a resource for cooperative extension. California: University of California. Statewide Integrated Pest Management Project. Division of Agriculture and Natural Resources, v.2, p.200-10, 1995. FRANÇA, F.H.; VILLAS-BÔAS, G.L.; BRANCO, M.C. Ocorrência de Bemisia argentifolii Bellows \& Perring (Homoptera: Aleyrodidae) no Distrito Federal. Anais da Sociedade Entomológica do Brasil, v.25, n.2, p.369-72, 1996.

HOELMER, K.A.; OSBORNE, L.S.; YOKOMI, R.K. Association of sweetpotato whitefly with squash silverleaf. In: YOKOMI, R.K.; NARAYANAN, K.R. Taxonomy, Biology, Damage, Control and Management, v.1, p.537-56, 1991a.

HOELMER, K.A.; OSBORNE, L.S.; YOKOMI, R.K. Foliage disorders in Florida associated with feeding by sweetpotato whitefly, Bemisia tabaci. Florida Entomologist, v.74, n.1, p.162-6, 1991b.

HOROWITZ, A.R.; ISHAAYA, I. Chemical control of Bemisia-manegement and application. In GERLING, D.; MAYER, R.T. (Eds.), Bemisia 1995: taxonomy, biology, damage control and manegement. Intercept Ltd., 1995. p.537-56.

LARA, F.M. Princípios de resistência de plantas a insetos. São Paulo: Ícone. 1991. 336p.

LIN, H.; KOGAN, M.; FISHER, D. Induced resistance in soybean to the Mexican bean beetle (Coleoptera: Coccinellidae): comparisons of inducing factors. 
Environmental Entomology, v.19, p.1852-7, 1990. LIU, T.X.; OETING, R.D. Morphological comparisons of three species of whiteflies (Homoptera: Aleyrodidae) found on greenhouse-grown plants. Georgia: The Georgia Agricultural Experiment Stations/College of Agricultural and Environmental Sciences/The University of Georgia, 1993. 11p. (Boletim de Pesquisa, 12)

LOURENÇÃO, A.L.; NAGAI, H. Surtos populacionais de Bemisia tabaci no Estado de São Paulo. Bragantia, v.53, n.1, p.53-9, 1994.

MARTINEZ S.S (Ed.). O nim Azadirachta indica natureza, usos múltiplos, produção. Londrina: IAPAR. 2002. 142p.

MAZZONETTO, F.; VENDRAMIM, J.D. Efeito de pós de origem vegetal sobre Acanthoscelides obtectus (Say) (Coleoptera: Bruchidae) em feijão armazenado. Neotropical Entomology, v.32, p.145-9, 2003.

NAGAI, H. et al. Ocorrência da "folha prateada de aboboreira" associada à mosca branca (Bemisia tabaci). Horticultura Brasileira, v.10, n.1, p.62, 1992.

NORMAN, J.W. et al. Management of silverleaf whitefly: A comprehensive manual on the biology, economic impact and control tactics. Washington: USDA, 1986. 13p. OLIVEIRA, M.R.V.; SILVA, O.L.R.E. Mosca-branca, Bemisia argentifolli (Homoptera: Aleyrodidae) e sua ocorrência no Brasil. Brasília: Ministério da Agricultura e do Abastecimento/Departamento de Defesa e Inspeção Vegetal, 1997. 16p. (Alerta Fitossanitário, 1). SAS Institute. SAS/STAT users guide. Cary, NC, 2001. SCHMALSTIG, J.C.; MCAUSLANE, H.J. Developmental anatomy of zucchini leaves with squash silverleaf disorder caused by the silverleaf whitefly. Journal of the American Society for Horticultural Science, v.126, n.5, p.544-54, 2001.

SILVA, L.D. et al. Monitoramento da suscetibilidade a inseticidas em populações de Bemisia tabaci (Gennadius) (Hemiptera: Aleyrodidae) no Brasil. Neotropical Entomology, v.38, n.1, p.116-25, 2009.

SOUZA, A.P.; VENDRAMIM, J.D. Atividade ovicida de extratos aquosos de meliáceas sobre a mosca-branca Bemisia tabaci (Gennadius) biótipo B em tomateiro. Scientia Agrícola, v.57, n.3, p.403-6, 2000.

SOUZA, A.P.; VENDRAMIM, J.D. Atividade inseticida de extratos aquososde meliáceas sobre a mosca-branca Bemisia tabaci (Genn.) biótipo B (Hemiptera: Aleyrodidae). Neotropical Entomology, v.30, n.1, p.1337, 2001.

SUMMERS, C.G.; STAPLETON, J.J. Use of UV reflective mulch to delay the colonization and reduce the severity of Bemisia argentifolii (Homoptera: Aleyrodidae) infestations in cucurbits. Crop Protection, v.10, n.21, p.921-8, 2002.

VAN LENTEREN, J.C.; NOLDUS, L.P.J.J. Whitefly-plant relationships: behavioral and ecological aspects. In: GERLING, D. Whiteflies: their bionomics, pest status and manegement. Andover: Intercept, 1990. p.47-90.

VILLAS BÔAS, G.L. et al. Manejo integrado da moscabranca Bemisia argentifolii. Brasília: EMBRAPA-CNPH, 1997. 11p. (EMBRAPA-CNPH. Circular técnica da EMBRAPA Hortaliças, 9).

YOKOMI, R.K.; HOELMER, K.A.; OSBORNE, L.S. Relationships between the sweetpotato whitefly and the squash silverleaf disorder. Phytopathology, v.80, n.10, p.895-900, 1990a.

YOKOMI, R.K.; HOELMER, K.A.; OSBORNE, L.S. Studies on etiology of squash silverleaf at Orlando. In: YOKOMI, R.K.; NARAYANAN, K.R.; SCHUSTER, D.J. (Eds.). Sweetpotato whitefly mediated vegetable disorders in Florida. Gainesville: Institute of Food and Agricultural Sciences, 1990b. p.23-4. 